\title{
LINGUAGEM E TRADIÇÃO EM HANS GEORG GADAMER
}

\section{LANGUAGE AND TRADITION IN HANS GEORG GADAMER}

\author{
Pedro Ramos Ventura ${ }^{1}$
}

Recebido em: 31/03/2014 Aprovado em: 23/03/2015

\section{RESUMO}

O propósito deste artigo é compreender as relações existentes entre a linguagem e a tradição em Hans G. Gadamer a partir das obras Verdades e Métodos I e II. A compreensão ou a incompreensão, segundo Gadamer, consistem um fenômeno de linguagem. A linguagem é autônoma, e a língua é desenvolvida em contextos e culturas diferentes. Cada cultura cultiva suas tradições, e a linguagem não está desvinculada da tradição cultural humana e histórica. A linguagem que temos é também limitada quando nos deparamos com algum tipo de fenômeno que nos causa admiração, que nos deixa "mudos" ou estupefatos, isto é, sem palavras. Diante desse fenômeno, a linguagem nos falta, pois não haveria palavras para explicar aquilo que apreendemos. Ficar sem fala, segundo Gadamer, é um modo pelo qual estamos apenas começando a dizer e não finalizando nossa fala.

Palavras-chave: Gadamer; Linguagem; Tradição; Língua e Cultura.

\begin{abstract}
This paper aims to understand the relationship between language and tradition in Hans G. Gadamer from the works Truth and Method I and II. The understanding or misunderstanding, according to Gadamer, consist in a language phenomenon. The language is autonomous, and the language is developed in different contexts and cultures. Each culture cultivates its traditions, and language is not disconnected from the human and historical cultural tradition. The language we have is also limited when we face some kind of phenomenon that makes us wonder, "dumb" or stupefied, that is, without words. Given this phenomenon, we lack the language, because there would be no words to explain what we learn. To be speechless, according to Gadamer, is one way in which we are just beginning to say and not finishing our speech.
\end{abstract}

Keywords: Gadamer; Language; Tradition; Language and Culture 


\section{Introdução}

$\mathrm{O}$ presente artigo tem interesse em explorar alguns aspectos conceituais em Verdade e Método I e II de Gadamer para perceber a finalidade da linguagem humana e o modo como esta se relaciona à tradição. Gadamer concedeu ênfase especial à tradição como princípio fundamental para explicar a complexa relação entre os diferentes contextos e as interlocuções dos seres humanos entre si. O intuito deste texto consiste, assim, em mostrar pontos relevantes das ideias filosóficas de Gadamer, abordando suas contribuições, seus paradoxos e suas lacunas, os quais merecem nossa atenção.

A linguagem corresponde ao que Gadamer chama de compreender o dizível e o indizível. Sendo o homem é um ser vivo dotado de linguagem, esta não pode ser reduzida a um sistema de signos, pois constitui a linguagem do próprio Ser.

A linguagem pertence ao Ser; o Ser pode ser inteligível e explicitado na linguagem, ao passo que a língua é inata, de modo que não se reduz à tradição ou à cultura, mas é própria dos agentes falantes.

A linguagem consiste na preparação de um instrumento com vista ao acordo, tal como ocorre na conversação, em que coincide com a realização mesma do compreender e do chegar a um acordo com o outro. Para Gadamer, no entanto, a linguagem não é um instrumento ou uma ferramenta que usamos e descartamos a qualquer instante: a linguagem não é descartável, pois ela expressa o próprio Ser.

Diante disso, o propósito deste trabalho é discutir os conceitos de Ser, linguagem, língua e cultura, considerando-se que há outros filósofos contemporâneos que se opõem ao método hermenêutico de Gadamer sobre a filosofia da linguagem. Assim, quer-se comparar e confrontar suas ideias e perceber quais os benefícios que trouxeram para a filosofia e para a ciência hoje. Para isso, este texto está subdivido em seis partes, além desta introdução: o conceito de lingua- gem, o conceito de tradição, o conceito de língua, o conceito de cultura, conclusão e referências bibliográficas.

\section{$2 \mathrm{O}$ conceito de linguagem em Gadamer}

Para Gadamer, a linguagem não deve ser um objeto de análise delimitável por conceitos. Wittgenstein, por exemplo, renunciou seu primeiro projeto, o da linguagem matemática, ideal e perfeita, em que é possível abstrair toda a realidade. Para Wittgenstein, a linguagem não consiste em regras e não está delimitada na autoridade apenas da tradição como supôs Gadamer, para que a linguagem consiste em regras e técnicas de jogos linguísticos.

Há desacordos entre Gadamer e Wittgenstein, uma vez que cada qual parte de pressupostos epistemológicos condizentes com suas crenças e tradições filosóficas. Gadamer entende que a linguagem vai além da linguagem simbólica, isto é, da linguagem dizível, incluindo, assim, aquilo que não se pode dizer ou falar. Já Wittgenstein, no Tractatus Philosophicus, seu primeiro e ambicioso projeto, assegura que aquilo que não se pode dizer deve ser calado, ainda que mais tarde apresente um pensamento distinto na obra Investigações Filosóficas.

Para Gadamer, mais importante que o sistema de regras das prescrições do jogo, ou seja, as regras que permitem a realização da língua, é o acontecimento de como tomar parte nesse jogo. Já Wittgenstein tem uma preocupação com a finalidade do próprio jogo da linguagem, querendo mostrar suas regras de funcionamento e descrever seus diversos jogos, instrumentalizando-a. Gadamer não tem uma preocupação utilitária (instrumental) do jogo, mas acredita que é no jogar e no acontecer da linguagem que esta instaura e explicita a experiência do sentido da vida humana.

Todo mundo sabe, porém, que não é possível um falar terminológico, nos moldes da exatidão do cálculo em 
símbolo matemático. É verdade que o falar lança mão de termos. Mas isso significa que esses termos se incorporam constantemente no processo de entendimento, recendo sua função própria de linguagem no seio desse processo. [...] O uso filosófico da linguagem, como vimos, não possui outra credencial a não ser que se dá na linguagem (GADAMER, 2002. p. 102).

É evidente, assim, que Gadamer rejeita o conceito de linguagem ou de língua wittgensteiniana, aliás, daquilo que se denomina o $1^{\circ}$ Wittegenstein o da linguagem matemática. Gadamer compreende a linguagem como pertencente ao Ser, sem barreiras linguísticas e sem delimitar o próprio Ser. Estamos de acordo que não podemos delimitar o próprio Ser! Porém, é pertinente perguntar se o Ser a que Gadamer se refere em Verdade e Método inclui também os animais que possuem um tipo de "capacidade racional" e cognitiva. A questão que se instaura é: o Ser é um tipo de "animal racional e cognoscente"?

Para Wittgenstein, em sua obra Investigação Filosófica, a análise da linguagem decorre da necessidade de observar seus diferentes usos e seus diferentes jogos linguísticos, de modo que os homens e os filósofos devem apenas ver e deixar tudo como é, ou seja, não extrapolar a linguagem, pois esta deve ser sempre comunicável. A nós, que fazemos parte da comunidade linguística, não cabe inventar ou reinventar a própria linguagem, mas apenas observar o que já está dado. Disso decorre que a linguagem é estática: não sofre mudanças ou transformações. No entanto, a linguagem é uma construção humana, de forma que cada grupo da comunidade linguística têm seus códigos e suas formas conceptuais de comunicar. A divergência entre Gadamer e Wittegenstein é que para aquele a linguagem pode extrapolar os limites do Ser, enquanto que para este a linguagem limita o Ser, ou seja, a linguagem é restrita apenas àquilo que pode ser dizível e expressado por um raciocínio matemático, sem extrapolar os limites gramaticais e da razão.

Para Wittgenstein, compreender uma linguagem é dominar uma técnica, o que é possível por meio da observação dos jogos de linguagem específicos. Gadamer não está interessado em técnicas para compreender, dominar e conhecer, pois compreender não significa para ele dominar uma técnica ou um conjunto de regras; o Ser que pode ser compreendido é linguagem. Ou seja, a linguagem não é só aquela que falamos, existem possibilidades de extrapolarmos os limites da razão para comunicarmos aquilo que ainda está por vir!

Acredita-se que o aprendizado da linguagem consiste no fato de se dá nomes aos objetos: homens, formas, cores, dores, estado de espirito, numero, etc. (WITTEGENSTEIN, 1999, p. 26).

Wittegenstein, na obra Investigação Filosófica, parece mudar o curso de seu pensamento filosófico no que concerne aos signos linguísticos, outrora rejeitados no Tractatus Philosophicus. $\mathrm{Na}$ Investigação Filosófica, a linguagem é prática e objetiva. O homem racional pode nomear coisas, ao passo que os animais são desprovidos de tais capacidades racionais, isto é, de nomear e fazer o uso da língua, assim como de dominar a própria linguagem!

Para o filósofo:

a palavra "este" no jogo da linguagem, ou a palavra "isto" na elucidação abstenha "isto" chama... Se se quiser evitar confusão, é melhor não dizer que essas denominaram algo. E, estranhamente, já foi dito que a palavra "este" é o nome específico. Tudo que chamamos sem mais de "nome" é dito apenas num sentido inexato, aproximativo (WITTEGENSTEIN, 1999, p. 26).

Enquanto que para um a linguagem é o próprio Ser arraigado na tradi- 
ção e na cultura, para outro a linguagem está reduzida a uma técnica dos falantes, ou seja, àquilo que pode ser comunicável e compreendido na língua que se pretende falar.

O homem pode se comunicar e falar tudo o que pensa. É pela capacidade de se comunicar que os sujeitos podem pensar os conceitos comuns, como também viver em sociedade plural, partindo do pressuposto de que o homem é um ser dotado de linguagem. O homem é privilegiado nesse sentido se comparado ao animal não racional, que não possui a capacidade de interação comunicacional.

A função da filosofia da linguagem e da ciência da linguagem por Wilhelm Von Humboldt não representou, contudo, uma autentica restauração da visão aristotélica. Como seu objeto de investigação eram os idiomas dos povos, abriu- se um caminho de conhecimento que pode esclarecer de maneira nova e fecunda a diversidade dos povos e dos tempos e a essência humana comum a eles subjacente. Mas o que definiu aqui o horizonte da pergunta pelo homem e pela linguagem foi apenas admitir no homem uma faculdade e esclarecer o regimento estrutural dessa faculdade que chamamos de gramatica, sintaxe, vocabulário da linguagem. No espelho da linguagem, podiam se reconhecer as cosmovisões dos povos, conhecer detalhadamente a estrutura de sua cultura um bom exemplo é o conhecimento do estágio cultural da constituição dos povos. [...] Mesmo assim, nesse modo de pensar, o fenômeno da linguagem só adquire o significado de um campo de expressão eminente, no qual é possível estudar a essência do homem e sua evolução na história (GADAMER, 2002, p. 175).

Gadamer pensa a linguagem como algo constituinte do sujeito, que não está limitada ou presa a nenhum tipo de regra ou conceito clássico. Ele defende que todo pensar sobre a linguagem, pelo contrário, é alcançado pela própria linguagem, já que o sujeito só pode pensar dentro de uma linguagem. A linguagem, segundo Wittegenstein, não está presa a um modelo de critério que constitui a fala. A língua, como ocorre com a linguagem, pode romper fronteiras, de modo que o indizível alcança compreensão hermenêutica dentro de um contexto específico. Gadamer não explica se todo Ser tem a capacidade de pensar, abstrair, julgar e conceituar, bem como se o Ser é universal, isto é, não excludente.

\section{0 conceito de tradição em Gadamer}

A tradição em Gadamer está inter-relacionada com a linguagem. Tal relação faz parte do sujeito falante dentro de um contexto, de forma que o sujeito participa dessa tradição contextual e hermenêutica. O que Gadamer entende por tradição? Para Gadamer, a tradição é o momento da liberdade e da própria história. A tradição mais autêntica e venerável não se realiza naturalmente em virtude da capacidade de permanência daquilo que singularmente está aí, mas necessita ser afirmada, assumida e cultivada.

A tradição é essencialmente conservação e como tal sempre está atuante nas mudanças históricas. No entanto, a conservação é um ato da razão, ainda que caracterizado pelo fato de não atrair a atenção sobre si. Essa é a razão por que as inovações, os planejamentos intentem mostrar-se como única ação e resultado da razão. Isso, no entanto, apenas parece ser assim. Inclusive quando a vida sofre suas transformações mais tumultuadas, como em tempo revolucionários, em meio à suposta mudança de todas as coisas conserva-se muito mais do que era antigo do que se poderia crer, integrando-se com o novo numa nova forma de validez. Em todo caso, a conservação representa uma conduta tão livre como a destruição e a inovação. Tanto a crítica à tradição, como a sua reabilitação romântica, ficam muito aquém de seu verdadeiro ser histórico (GADAMER, 2002, p. 423). 
Gadamer postula que a tradição deve ser assumida pelos sujeitos, pois é nela que o indivíduo se assumiu como tal. A tradição é um ato puramente de conservação daquilo que valorizamos. Disso decore que a tradição é um ato racional e um desenrolar histórico, que está em constantes mudanças, as quais só ocorrem em função do homem racional. Contudo, a tradição, em outros contextos, não provoca mudança no homem tal como pretende Gadamer. Os valores morais, assim como os vários tipos possíveis de racionalidades, contrapõem-se ao pensamento gadameriano.

John McDowell'2, em seu livro Mind and World (Mente e Mundo, 1942) discorda de Gadamer quanto ao conceito de tradição. Por alguma razão, McDowell não desenvolve a questão. Gadamer recorre à história e à tradição para subsidiar suas argumentações.

Para o filósofo,

Os costumes são dotados livremente, mas não criados por livre inspiração nem sua validez nela se fundamenta. É isso, precisamente que denominamos tradição: o fundamento de sua validez. E nossa divida para com o romantismo é justamente essa correção do Aufklarung, no sentido de reconhecer que, à margem dos fundamentos da razão, a tradição conserva algum direito e determina amplamente as nossas instituições e comportamentos. A superioridade da ética antiga sobre a filosofia moral da idade moderna se caracteriza precisamente pelo fato de que, com base no caráter indispensável da tradição, ela fundamenta a passagem da ética à política, a arte, legislação correta (GADAMER, 2002, p. 421-422).

2 É um filósofo contemporâneo que foi membro do University College da Universidade de Oxford. Atualmente, é professor na Universidade de Pittsburgh e pesquisa filosofia da mente e filosofia da linguagem. Na década de 1970, investigou a semântica da linguagem natural. Seu trabalho foi muito influenciado por Ludwig Wittgenstein, Peter Strawson, David Wiggins, Gareth Evans, Wilfrid Sellars e vários outros pensadores. Seu mais recente trabalho em filosofia é: Mind and World, em que há uma explicação controversa sobre a justificação empírica de crenças, desde as críticas de Hegel a Kant, sendo fortemente Influenciado por Richard Rorty.
Para Gadamer, é importante refletir sobre o método epistemológico dominante a fim de saber se a consciência histórica conseguiu diferenciar nossos comportamentos científicos quanto àquele comportamento natural em relação ao passado. Nosso comportamento em relação ao passado, insiste Gadamer, é de confirmar constantemente a tradição.

Antes, encontramos sempre em tradições, e esse nosso estar dentro delas não é um comportamento objetivador, de tal modo que o que diz a tradição fosse pensado como estranho ou alheio - isso já é sempre algo próprio, exemplar e intimidamente, um reconhecer-se, no qual, para nosso juízo histórico posterior, quase já não se divisa conhecimento, porém a mais singela e inocente transformação da tradição (GADAMER, 2002, p. 423).

Gadamer argumenta que a tradição, assim como a linguagem, é algo que faz parte da subjetividade dos sujeitos. Porém, a tradição, como é o caso da linguagem, constantemente passa por mudanças. "O efeito da tradição que sobrevive e, os efeitos da investigação histórica formam uma unidade de efeito, cuja análise só poderia encontrar uma trama de efeitos recíprocos" (GADAMER, 2002, p. 435). Em outras palavras, o que Gadamer pretende dizer é: existe uma reciprocidade entre o comportamento histórico e o da tradição, de modo que o efeito de um é também o efeito de outro. Portanto, tanto a tradição como o comportamento histórico são inseparáveis no contexto hermenêutico.

Habermas, outro filósofo que objeta o conceito de tradição gadameriana, defende que a tradição não pode ter um peso absoluto, pois essa seria uma concepção ingênua de que a tradição não perde sua força pela ação da consciência histórico-factual.

\section{Segundo Habermas:}

Que em el fondo Gadamer sostiene una autocomprensión de la herma- 
néutica que absolutiza el peso de la tradición. La absolutizacón de la tradicion mantiene la concepción ingênua de que las tradiciones no pierden su fuerza por la acción de la consciência histórico- efectual. Sin embargo, de hecho la reflexión desplaza el peso desde la autoridade incontestada de las tradiciones hacia el poder de la razón. La reflexión es capz de desvelar la aparente absolutez de la tradición. Ya que la reflexión hace consciente la génesis de tradición a la que ella misma pertenece y sobre la que se vuelve, está capacitada para romper el dogmatismo del mundo vivido, su caráter incontestable. Hay uma via para la crítica (apud ORAA, 2000, p. 499).

Habermas não concorda com a ideia de que a tradição é absoluta e fechada. Para ele, o caminho da reflexão pode abrir portas para novas ideias e novas formas de ver o mundo e a própria história. A reflexão consciente possibilita verificar os modelos, os rótulos, as crenças e os dogmas e confrontá-los com pressupostos capazes de responder aos paradoxos filosóficos, o que constitui exercício próprio do filosofar. Habermas

defende um concepto de reflexión donde la razón realiza la experiência del retorno sobre si misma y encuentra em su próprio senso um dinamismo crítico, emancipador, respecto a las concepciones dogmáticas (interés por la emancipación) (apud ORAA, 2000, p. 500).

A crítica de Habermas a Gadamer é em relação à tradição. Gadamer limita o exercício do pensamento filosófico, fazendo da tradição uma autoridade máxima para reflexão acerca do pensamento filosófico. Segundo Habermas, a consciência histórico-factual está aberta e em constante dinamismo: sua força reside na insondável capacidade da racionalidade humana.

Habermas critica a tradição como a teoria do produto simbólico elaborado pela própria humanidade, pois entende que a tradição pode sofrer um tipo de manipulação semântica, chegando a aparecer como mais um produto na esfera capitalista. Habermas critica Gadamer, afirmando que "transforma a intelecção da estrutura preconceitual da compreensão numa reabilitação do preconceito enquanto tal" (HABERMAS, 1987, p. 16).

A tradição é um conceito que delimita determinado grupo de agentes morais, mas não implica necessariamente códigos infalíveis. A tradição moderna valoriza a troca de experiência, em um contexto em que o avanço da tecnologia vem quebrando paradigmas e preconceitos e confrontando nossa visão de mundo, levando-nos a redesenhar e ponderar nossa maneira de conceber o mundo. $\mathrm{O}$ intercâmbio de conhecimentos científicos é essencial, porque interconecta o mundo e rompe aos poucos com os modelos hegemônicos de certas crenças arraigadas nas tradições. Isso só acontece quando a reflexão expande seu horizonte para além daquilo que já está dado.

\section{0 conceito de língua}

[...] as línguas são produtos da força linguística originária do espírito humano, e cada língua está em condições de alcançar o objetivo geral que se procura com essa força natural do homem. Mas isso não exclui, e até legitima, o fato de que a comparação das línguas procura um padrão de perfeição, segundo a qual elas se diferenciam. Pois é comum a todas as línguas "o impulso a dar existência na realidade à ideia da perfeição linguística" e a tarefa do linguista se orienta precisamente em investigar até que ponto e com que meios se aproximam as diversas línguas a esta ideia (GADAMER, 1997, p. 638).

O ponto de partida de Gadamer é mostrar que o conceito de língua é originário do próprio homem, o que quer dizer que a língua se manifesta a partir do esforço humano, tem um objetivo 
geral e busca um padrão de aperfeiçoamento. Para Humboldt ${ }^{3}$ (apud GADAMER, 2002, p. 638), "existe diferença de perfeição entre as línguas, não há um modelo prévio da qual submete à força do complexo fenômeno da língua".

[...] entre o indivíduo e a língua existe uma relação mútua que confere ao homem, face a língua, uma certa liberdade. Tampouco se engana, com respeito ao fato de que é uma liberdade limitada, na medida em que cada língua, face ao lado em cada caso, forma um modo peculiar de existência, que faz que nela se experimente, com particular nitidez e vivacidade, "até que ponto, inclusive o passado mais longínquo, continua vinculando-se ao sentimento do presente, já que a língua passou pelas sensações das gerações anteriores e conservou em si o hálito daquelas". Humboldt consegue conservar a vida histórica do espírito, inclusive na linguagem concebida como forma. A fundamentação do fenômeno da linguagem no conceito da força linguística confere ao conceito da forma interior uma legitimação própria que faz justiça à mobilidade histórica da vida da linguagem (GADAMER, 2002, p. 640).

Para Humboldt, a linguagem humana é como um sistema governado por regras, e não uma coleção de palavras e frases acompanhadas de significados. Humboldt vai de encontro a Gadamer no que diz respeito às regras fechadas da linguagem. Para Gadamer, a língua ou a linguagem é desprovida de regras fechadas, de modo que é o Ser em si mesmo que se manifesta a partir da linguagem. Esta é, assim, o próprio Ser, e a língua pode estar carregada de significados, podendo expressar o dizível e o indizível.

Humboldt parte de pressuposto de que a linguagem ou a língua tem um padrão de regras; já Gadamer acredita que a linguagem faz parte da vida histórica dos indivíduos.

\footnotetext{
3 Wilhelm von Humboldt (1767-1835), filósofo da linguagem.
}

Wittegenstein, na obra Investigações Filosóficas, incorpora outra filosofia da linguagem, não mais utilizando a tradição para justificar a autoridade do conhecimento. Nessa obra, defende que a língua ou a palavra nada mais é que um tipo de jogo sem regras. Para ele, não existe limite na língua ou na palavra: "o emprego da palavra não está regulamentado; o jogo que jogamos com ela não está regulamentado. Ele não está inteiramente limitado por regras" (WITTGENSTEIN, 1999, p. 236).

Para Gadamer, o conceito de língua não pode representar uma abstração, como é o caso das regras formais que Humboldt defende, já que a forma linguística e o seu conteúdo na tradição, de nenhuma forma, podem ser separados da experiência hermenêutica. Gadamer sustenta a ideia de que cada língua é uma "acepção do mundo", ou seja, não é uma qualidade de representante de um determinado tipo de língua, mas uma virtude daquilo que foi dito e transmitido por meio da tradição.

Humboldt aproxima-se de Gadamer no que concerne à essência da linguagem, ao defender que esta é uma realização viva do falar. Humboldt e Wittegenstein objetam, no entanto, a tradição como constituinte da fala ou da linguagem; não há limite para a dialogalização da palavra.

Segundo Gadamer,

Humboldt reconheceu a essência da linguagem, como a realização viva do falar, a energia linguística, rompendo assim com o dogmatismo dos gramáticos. Partindo do conceito da força, que guia todo seu pensamento sobre a linguagem, corrige também, de um modo especial, a questão da origem da linguagem, que estava particularmente sobrecarregada por questionamentos teológicos. [...] Face a essa classe de construções, ele sublinha, com razão, que a linguagem é humana desde seu começo. Essa constatação não somente modifica o sentido da questão da 
origem da linguagem. Ela é a base de uma perspectiva antropológica de amplo alcance (2002, p. 642).

A linguagem não é um apetrecho humano, mas indica que o homem tem o mundo e está no mundo. Para o homem, o mundo está "aí como mundo" de forma que não há existência para nenhum outro ser vivo nele posto. A existência do mundo está constituída linguisticamente, tal como acreditava Humboldt ao defender que as línguas são acepções de mundo.

A humanidade originária da linguagem significa, pois, ao mesmo tempo, a linguisticidade originária do estar no mundo do homem. [...] ter o mundo quer dizer comportar-se para com o mundo. Mas comportar-se para com o mundo exige, por sua vez, que nos mantenhamos tão livres, face ao que nos vem ao encontro a partir do mundo, que conseguimos pô-lo ante nós tal como é. Essa capacidade é tanto ter mundo como ter linguagem (GADAMER, 2002, p. 643).

A linguagem afirma ao indivíduo que pertence a uma comunidade linguística uma espécie de existência individual ou autônoma, que introduz o indivíduo, quando este nela cresce, em uma relação com o mundo e em determinado comportamento com relação a ele (mundo). A linguagem gadameriana não afirma uma existência autônoma face ao mundo que fala por meio dela. "Não somente o mundo é o mundo, apenas, na medida em que a linguagem só tem a verdadeira existência no fato de que nela se representa o mundo" (GADAMAER, 2002, p. 235).

Para Gadamer,

O entendimento sobre uma língua não é o caso normal do entendimento, mas o caso especial de um acordo com respeito a um instrumento, com respeito a um sistema de signos que não têm seu ser na conversação, mas que serve como meio a objetivos informativos (2002, p. 648).
A língua é um instrumento próprio do homem falante que está no mundo. $\mathrm{O}$ indivíduo só compreende a si mesmo a partir de sua língua: é ela que nos constitui como sujeitos pertencentes a uma mesma comunidade de fala. A língua não é um sistema fechado, representado apenas por signos, mas vai além de seus limites conceituais linguísticos. Tanto Humboldt quanto Gadamer contribuíram para os estudos linguísticos, cada qual com seus pressupostos teóricos. Gadamer explicitou em várias passagens de suas reflexões que a linguagem ou a língua é, por essência, a linguagem da conversação e que os indivíduos, em qualquer contexto, possuem essa capacidade conversacional. No caso de surdos, mudos e pessoas em estado de degeneração mental, caberia questionar se estes também possuem tais capacidades para a comunicação conversacional que traspassam os limites da linguagem, da língua e do próprio Ser.

\section{O conceito de cultura em Gadamer}

[...] a herança cultural dos povos é antes de tudo uma tradição de formas e artes de domínio, de ideias, de liberdade, teleologias de ordem etc. Quem poderá negar que nossas possibilidades humanas mais próprias não consistem simplesmente no dizer? Deveríamos admitir que toda experiência do mundo estruturada na linguagem experimenta o mundo e não a linguagem. $\mathrm{O}$ que articulamos no debate a cerca da linguagem não constitui um encontro com a realidade? $\mathrm{O}$ encontro com o domínio e a falta de liberdade leva à formação de nossas ideias políticas (GADAMER, 2002, p. 239).

Para Gadamer, as culturas dos povos são expressas em suas tradições. Tais tradições são uma espécie de artes de "dominação", em que as culturas sublevam suas ideias e visões de mundo, ora em um espírito criativo, ora em um espírito de liberdade ou de opressão. Estar no mundo, diz Gadamer, é estar em um mundo de experiência pré-es- 
quematizado, "dialogando com outras pessoas, pessoas que pensam diferente, aceitando um novo exame crítico e novas experiências" (2002, p. 25).

É importante ressaltar, assim, que nossas experiências no mundo nos permitem dialogar com os outros e nos percebermos no outro. Esse outro que se apresenta a nós também carrega uma bagagem de experiências que podem ser compartilhadas, levando a reflexões sobre nossas construções ideológicas e políticas.

O conceito de cultura é também traduzido por Gadamer como contexto, e contexto, em Gadamer, é uma questão hermenêutica. A hermenêutica não é apenas o estudo de interpretação de texto, mas da maneira como cada povo se articula a partir de suas próprias realidades, que não são homogêneas, manifestandose nas mais variadas formas culturais.

Segundo o filósofo,

A linguagem é histórica, é o repositório do modo de ver de toda a nossa cultura. Resumindo, a própria interpretação é histórica, e se tentarmos fazer dela qualquer outra coisa acrescentando-lhe ou tirando-lhe algo, empobrecemos a interpretação e empobrecemos a nós mesmo (GADAMER, 2002, p. 255).

A cultura dos povos manifesta-se na linguagem, na forma de interpretar o mundo e a história. A história, por conseguinte, não é carregada das mesmas experiências, mas pode ser compartilhada à medida que estamos abertos para escutar e aprender com as experiências de outros. Nessa perspectiva, Gadamer sustenta que a cultura é mediada por esses jogos tradicionais da compreensão hermenêutica, em que interpretamos e compreendemos uns aos outros.

O movimento hermenêutico possibilita a realização do todo dos indivíduos. Isso significa que o jogo da cultura não está preso a um modelo único de viver, pois permite que todos joguem e participem. Dessa forma, todos são participantes na construção de uma sociedade e todos fazem parte do jogo.
A pergunta, então, é: o que é uma cultura? Tal questão nos leva a pensar em um processo das manifestações sociais de um determinado grupo de pessoas, que "compartilham os mesmos pressupostos hermenêuticos de mundo". A cultura faz parte, assim, de um contexto hermenêutico, interpretado em um contínuo processo de movimentos e manifestações das mais variadas formas do Ser.

Para Gadamer, cultura é o contexto histórico-hermenêutico, em que os indivíduos se compreendem a partir de sua historicidade, dentro de um determinado contexto. Segundo ele, a hermenêutica não trata apenas das questões de interpretação de texto, pois, sendo ontológica, discute também o próprio Ser - o Ser que precisa ser compreendido fora e dentro de um contexto histórico e cultural.

\section{Considerações finais}

Portanto, Gadamer reveste-se da autoridade da tradição para sustentar suas ideias filosóficas. A tradição gadameriana é essencialmente conservação e, como tal, sempre está atuante nas mudanças históricas. No entanto, "a conservação é um ato da razão, ainda que caracterizado pelo fato de não atrair a atenção sobre si”' (GADAMER, 2002, p. 345). Esse é o motivo pelo qual as inovações e os planejamentos intentam se apresentar como única ação e resultado da razão. Isso, no entanto, apenas parece ser assim. Inclusive quando a vida sofre suas transformações mais tumultuadas, como em tempo revolucionários, em meio à suposta mudança de todas as coisas, conserva-se muito mais do que se poderia crer, integrando uma nova forma de validez. "Em todo caso, a conservação representa uma conduta tão livre como a destruição e a inovação. Tanto a crítica a tradição, como a sua reabilitação romântica, ficam muito aquém de seu verdadeiro Ser histórico" (HABERMAS; 1987, p. 27).

Para Gadamer, a ciência deve estar atrelada à autoridade da tradição, já que o conhecimento científico depende desse reconhecimento, sem o qual não há 
prestígio nenhum diante da comunidade científica. Há algumas objeções diretas e indiretas, como é o caso de McDowell, Habermas, Wittegenstein e Humboldt, para quem a tradição não é autoridade absoluta e inquestionável, sem a qual não se faz ciência. Para Habermas, por exemplo, o caminho da reflexão é capaz de elucidar o aparente dogma da tradição. A dogmatização da tradição gadameriana pode ser, então, rompida se ela se abrir para o campo da reflexão mediada por uma razão desprovida de preconceitos.

Qual é a gênese da filosofia de Gadamer? A hermenêutica é seu bojo filosófico, mas não a hermenêutica tradicional cristã, que se preocupa em interpretar textos sagrados. Gadamer, nesse sentido, deu grande salto, pois propôs uma hermenêutica plural, que passa da interpretação e compreensão de texto a uma reflexão ontológica do sujeito e do Ser. Esse sujeito se compreende não mais a partir de um contexto fechado, mas sim das várias formas possíveis de entender o mundo, com o auxílio da hermenêutica que extrapola as compreensões das relações humanas e dos limites impostos pela linguagem, que abarca significados. Desse modo, tem-se uma ressignificação do sujeito, do dizível e do indizível, em contraposição a Wittgenstein, para quem o homem, diante do que não pode ser dito, deve se calar.

Por outro lado, Gadamer ampliou horizontes nos campos da filosofia da linguagem, trazendo contribuições necessárias para compreensões culturais das línguas. Para o filósofo, a língua é inata e histórica; e a história evolui no tempo e no espaço, de forma que, tal como é a língua, não está presa a um sistema de regras. Gadamer não nega o signo como manifestação da fala, mas defende que a língua é um ato cultural e hermenêutico, que não tem limites ontológicos e que, portanto, não pode ficar reduzida somente a signos e a regras normativas.

Gadamer não abandona por absoluto a gramática normativa, porém não faz da língua um instrumento utilitário como meio para um fim único: a língua dá origem a uma liberdade que só acontece nesse intercâmbio diacrônico por meio da dialogização com o outro. Isto é, a língua não se configura apenas na sua utilidade, pois expressa o próprio Ser. Para Humboldt, a língua é fixada por regras, sendo é instrumento utilitário para a convivência humana. Gadamer não nega que a língua é para o uso humano, mas não parte do pressuposto humboldeano.

Portanto, somos diferentes culturalmente, de forma que cada povo tem suas peculiaridades. Por esse motivo restringir uma cultura a partir de uma única peculiaridade é empobrecer o ser humano, que, embora se configure na própria linguagem, é culturalmente multiforme e complexo hermeneuticamente. Gadamer restringiu o Ser apenas à linguagem e à tradição; o Ser perpassa a linguagem e a tradição. A pergunta que surge, então, é: o que é o Ser? O Ser de Gadamer não passa de uma representação, de um estilo de linguagem, porque o Ser não diz nada sobre o próprio homem se não o conceito em si mesmo, sem apresentar um sentido para descrever, de fato, a essência do próprio Ser.

\section{Referências}

1. HABERMAS, J. Dialética e Hermenêutica. Porto Alegre: Ed. L\&PM, 1987.

2. HANS, G. G. Verdade e Método. Traços fundamentais de uma hermenêutica filosófica. 4. ed. Petrópolis: Ed. Vozes. 2002.

$3 . \quad$ Verdade e Método I. Petrópolis: Ed. Vozes. 2002.

4. . Verdade e Método II. Petrópolis: Ed. Vozes. 2002.

5. ORAA, J. M. A. Pensar Con Gadamer y Habermas. Faculdade de Filosofia da U. C. P. Braga, 2000

6. WITTEGENSTAIN, L. Investigações Filosóficas. São Paulo: Ed. Nova Cultura, 1999. 